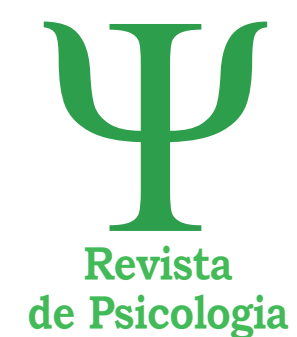

ISSN 2179-1740

\title{
SIGNIFICADOS DA HOMOFOBIA E DO PROJETO DE \\ VIDA PARA UM GRUPO DE ESTUDANTES HOMOSSEXUAIS
}

\author{
MEANINGS OF HOMOPHOBIA AND LIFE PROJECT FOR A HOMOSEXUAL STUDENT \\ GROUP
}

\author{
Washington Allysson Dantas Silva ${ }^{1}$
}

\section{Resumo}

Mesmo com o desenvolvimento das sociedades, a homofobia ainda é um problema persistente na contemporaneidade. Muito se discute sobre 0 sujeito que discrimina, mas pouco sobre como o alvo discriminado representa essa problemática e quais as repercussões desse preconceito ao longo de sua vida. Desse modo, diante da relevância deste tema, o presente artigo visa descrever os significados da homofobia e do projeto de vida para um grupo de jovens universitários homossexuais. Para esse fim, participaram quatro estudantes de diferentes cursos de graduação de uma universidade pública da região Nordeste do Brasil, os quais foram convidados a responder um conjunto de perguntas acerca de suas características sociodemográficas, além de como percebiam a relação entre homofobia e o seu planejamento pessoal sobre 0 futuro. As narrativas foram exploradas por meio da análise de conteúdo temática. De acordo com o grupo, a homofobia é significada como uma conduta hostil, motivada pelo preconceito frente ao comportamento homossexual, mas que não afeta diretamente o projeto de vida de suas vítimas. Os discursos que configuram esses significados são comentados com base nas consequências psicossociais vivenciadas por esses sujeitos, como exclusão e a necessidade de políticas públicas igualitárias.

Palavras-chave: Pesquisa qualitativa; Psicologia social; Homofobia; Preconceito.

\section{Abstract}

Even with the development of societies, homophobia remains a persistent problem in contemporary times. There is much discussion about the person who discriminates, but there are a few discussions about the discriminated subject concerning this prejudice on their personal representation and its repercussions throughout his life. Therefore, given the relevance of this topic, this article aims to describe the meanings of homophobia and the life project for a group of homosexual university students. To this end, four students from different undergraduate courses of a public university in the northeast region of Brazil participated, who were invited to answer a series of questions about their sociodemographic characteristics and their personal perception about homophobia and its relationship with personal planning on the future. The narratives were explored through thematic content analysis. According to the group, homophobia is hostile behavior, motivated by the prejudice against homosexual behavior, but that does not directly affect the lives of its victims. These meanings are commented on according to the psychosocial consequences experienced by these subjects, such as the exclusion and need for egalitarian public policies.

Keywords: Qualitative research; Social psychology; Homophobia; Prejudice. 1 Afiliação institucional: Universidade Federal da Paraíba, Programa de Pós-Graduação em Psicologia Social (PPGPS/UFPB). Brasil.
allysson_dantas@hotmail.com. https://orcid.org/0000-0002-0556-8936 
A homofobia é definida como uma atitude hostil frente aos homossexuais, podendo se manifestar de diferentes formas, desde comentários negativos a agressões e violências (Borrilo, 2015). Um fato histórico que exemplifica essa atitude social negativa diz respeito à vinculação do vírus da imunodeficiência humana (HIV) com os homossexuais: a mídia, em contato com associações políticas e sociais, atribuiu o termo "vírus gay" ao HIV devido a sua emergência inicial nesse grupo (Hammack, Frost, Meyer, \& Pletta, 2018). Esse fato favoreceu à estigmatização dos homossexuais frente à epidemia do HIVIAIDS, como apontam Parker e Aggleton (2001), uma vez que ser gay, nessa época, era sinônimo de risco ou de perigo para a sociedade.

Ainda hoje, o grupo homossexual é mundialmente perseguido de diferentes formas por pessoas intolerantes e preconceituosas. No Brasil, por exemplo, de acordo com o relatório do Grupo Gay da Bahia de 2017, 343 homossexuais haviam sido assassinados no ano de 2016, sendo a maior parte desses assassinatos praticados com arma de fogo, e $27 \%$ com armas brancas, incluindo também, pauladas, apedrejamento, dentre outros (GGB, 2017).

Mott (2006) discute que o ponto diferencial destes crimes para os demais ocorridos na sociedade é que na grande maioria dos casos, a agressão e a violência contra o homossexual ocorre simplesmente pelo fato de a pessoa ser homossexual, isto é, não há uma motivação concreta e diretiva (e.g., roubo, brigas, etc.) para essa violência. Essa é a expressão mais forte do comportamento homofóbico.

Dada a resistência pela manutenção do preconceito frente a esse grupo, o fenômeno da homofobia se apresenta como relevante na discussão sobre os significados quando buscamos compreender não apenas os significados que as pessoas atribuem aos homossexuais, mas também como os sujeitos desse grupo marcado pela perseguição social entendem ou atribuem sentidos à homofobia e como essa problemática repercute em seu projeto de vida.

\section{A HOMOFOBIA E O PROJETO DE VIDA ENQUANTO PROBLEMAS DE PESQUISA}

Na delimitação e formulação do problema de pesquisa, buscamos trabalhar com os fenômenos da homofobia e do projeto de vida, pautando esta problemática na população de estudantes homossexuais de uma universidade pública da região Nordeste do Brasil. Desse modo, o problema da pesquisa foi formulado com a seguinte pergunta: qual o significado da homofobia para universitários homossexuais e qual a sua interferência no projeto de vida individual?

Como brevemente discutido, a homofobia é uma atitude e, por conseguinte, é composta por três componentes: o componente avaliativo (e.g., julgamento negativo de um grupo), o afetivo (e.g., aversão a um grupo) e o conativo (e.g., uma tendência comportamental). Nessa perspectiva, a conduta homofóbica baseia-se na avaliação negativa da homossexualidade (ou do homossexual), vinculada a um afeto aversivo do sujeito homofóbico, podendo acarretar na discriminação da pessoa-alvo (Allport, 1954).

Por outro lado, acerca do Projeto de Vida, Catão (2007) discute que se trata de um fenômeno psicológico universal e que pressupõe três seguintes dimensões articuladas entre si: dimensão sócio-cognitiva, dimensão sócio-afetiva e dimensão espaço-temporal. Estas, favorecem a dialética entre o sujeito como transformador da natureza e a natureza como ferramenta de transformação do sujeito. 
O interesse para a execução desta pesquisa partiu, inicialmente, pela importância de se discutir sobre esses problemas diante de questões contemporâneas, a níveis nacional e internacional, que retratam a resistência do preconceito e discriminação frente ao grupo homossexual. Para exemplificar, abordamos alguns acontecimentos na Rússia, em 2017, que reforçam essa problemática.

Contrário à luta dos direitos e à expressão da afetividade da população gay, o então presidente Vladimir Putin estipulou uma lei que proibia qualquer protesto e/ou passeatas em defesa da população LGBT (Lésbicas, Gays, Bissexuais e Transgêneros) em Moscou até 0 ano de 2112, cujo descumprimento penaliza os manifestantes em até 5 anos de prisão. No mesmo ano, na região da Chechênia, também na Rússia, cerca de 100 homossexuais estiveram detidos em uma prisão sendo submetidos à agressão física e psicológica e à privação de direitos universais básicos, tais como a alimentação e abrigo. De acordo com a população local, essa prisão se tratou de uma política anti-homossexuais. Tal acontecimento ficou conhecido como o primeiro campo de concentração para a população gay desde o período nazista. Lydia Smith (2017), em uma reportagem sobre estes acontecimentos, relatou a fala de um prisioneiro que conseguiu escapar desse campo, retratando o cenário problemático enfrentado: "Some of the men have forcibly disappeared. Others were returned to their families barely alive from beatings. At least three men apparently have died since this brutal campaign began" (Smith, 2017, p. 01).

Não obstante, no contexto brasileiro, mesmo com a decisão da Suprema Corte acerca da penalização da homofobia enquanto um crime equiparado ao racismo, a discriminação sutil e institucional ainda é encontrada. Por exemplo, ao saber dessa decisão, o presidente do país concedeu entrevistas a jornais de circulação nacional afirmando que essa deliberação prejudicaria os próprios homossexuais e, ainda, que essa foi uma decisão tomada equivocadamente. Esse tipo de discurso sutilmente homofóbico, evocado pelo Chefe do Estado, amplia a justificativa para a construção desta pesquisa, salientando que Brasil é um país que registra uma morte motivada por homofobia a cada 23 horas (Sousa \& Arcoverde, 2019), como aponta o relatório anual de assassinatos de pessoas LGBTs produzido pelo Grupo Gay da Bahia (GGB, 2017).

\section{MÉTODO}

A pesquisa aqui retratada trata-se de um estudo do tipo descritivo, de abordagem metodológica qualitativa.

\section{Participantes}

Participaram deste estudo quatro estudantes de cursos de graduação da Universidade Federal da Paraíba, todos inseridos na área de humanidades. Com objetivo de preservar a identidade, a privacidade e a integridade dos participantes, cada sujeito foi nomeado com uma letra aleatória do alfabeto $(Y, T, U, K)$. A Tabela 1 apresenta as características dos participantes. 


\section{Instrumentos}

Foram utilizadas como estratégias de coleta de dados uma entrevista semiestruturada composta por perguntas sobre o tema (e.g., o que significa homofobia e/ou projeto de vida para você) e um questionário sociodemográfico sobre características dos participantes (e.g., idade, sexo, curso e renda).

\section{Procedimentos}

Todos os preceitos éticos de pesquisa com seres humanos foram seguidos na construção deste estudo. 0 projeto foi submetido à Plataforma Brasil e, após a aprovação (parecer n.3.473.300), foi entregue aos participantes 0 Termo de Consentimento Livre Esclarecido (TCLE), sendo abordados os objetivos, os riscos e os benefícios da pesquisa. Os participantes foram convidados a participar do estudo através de uma publicação nas redes sociais sobre o estudo, no qual estava sinalizado o dia e o horário para o encontro do grupo.

A entrevista foi realizada em grupo, a partir da técnica de grupo focal que, de acordo com Krueger e Casey (1996), consiste num tipo de entrevista realizada com um pequeno grupo formado por pessoas com características semelhantes, as quais, juntas, discutem sobre um tema focalizado. Neste estudo, a característica principal que unira os participantes foi o fato de todos serem autodeclarados não-heterossoxuais. Inicialmente, foi apresentado o TCLE e, após a assinatura de cada sujeito, a entrevista foi iniciada.

Tendo em vista que o vínculo entre o entrevistador e o grupo facilita a comunicação e o diálogo, no primeiro da entrevista foi solicitado que cada uma das pessoas se apresentasse, dizendo o nome, a idade, o curso e o que esperava para aquele dia, de modo geral. Após esse momento, foi feita a primeira pergunta versando sobre 0 tema (como apresentado na seção instrumentos). Especificamente, foi questionado aosparticipantes sobre 0 que eles entendiam por homofobia e projeto de vida, além de qual a relação destes temas para cada um. Toda a entrevista foi gravada e transcrita na íntegra. No final do encontro, foi solicitado que respondessem ao questionário sociodemográfico, sendo também entregue a versão do TCLE para os participantes. Todos os que se fizeram presentes no local concordaram com a utilização de seus relatos para fins de pesquisa, fazendo parte da amostra final deste estudo.

\section{ANÁLISE DE DADOS}

As entrevistas foram exploradas através da análise de conteúdo temática (Vala, 2003), tendo como referencial a perspectiva fenomenológica da pesquisa qualitativa (i.e., estudo dos significados).

\section{RESULTADOS E DISCUSSÃO}

A partir das análises das entrevistas (Vala, 2013), foram organizadas duas categorias de análise, sendo a seguir apresentadas e discutidas. 


\section{Os significados da homofobia}

Na primeira categoria, a homofobia como um conceito negativo pré-definido por alguém sobre o outro, foi constatado um sentido moral à homofobia enquanto uma lógica subjetiva de pensamento negativo direcionado a alguém dito como diferente, diante o padrão normativo vigente. Esta categoria é sinalizada pela discussão trazida pela participante $Y$ :

a homofobia é o desdobramento de preconceitos enraizados nos indivíduos, seguindo uma lógica de ter pré-noções sobre o assunto que estão ligadas a um valor moral negativo incutido na grande parcela da sociedade (...) é um pensamento negativo em relação ao outro (...) que além de carregar esse peso negativo se torna uma ação incontrolável sobre esses outros sujeitos ditos diferentes.

Enquanto categoria atitude discriminatória e vexativa contra um indivíduo LGBT, encontram-se concepções entrelaçadas à afetividade e ações direcionadas a algum homossexual, espelhadas na falta de compreensão à liberdade e à expressão individual dos sujeitos LGBT em sociedade.

homofobia é qualquer comentário ou ação pejorativa que venha a diminuir ou ofender, tanto fisicamente como psicologicamente, a comunidade LGBT (T).

a homofobia é o ódio dirigido às pessoas que são homossexuais através de olhares, gestos e atitudes por outras pessoas que não conseguem compreender, aceitar e viver numa sociedade onde a sexualidade é livre e diversa, e é um direito individual que faz parte da identidade de cada pessoa e da sua própria expressão de vida $(U)$.

No debate entre os resultados encontrados nos discursos dos sujeitos e as teorias possíveis de explicação do conteúdo, observa-se uma aproximação deste campo conceitual com a discussão trazida por Gordon Allport acerca do significa do preconceito, entendido pelo autor como "uma atitude evitativa ou hostil contra uma pessoa que pertence a um grupo simplesmente porque ela pertence àquele grupo, e está, portanto, presumido que objetivamente ela tem as qualidades atribuídas ao grupo" (Allport, 1954, p. 7).

Neste sentido, Tajfel (1972) elabora que as relações grupais são desenvolvidas de forma positiva entre os participantes de um mesmo grupo (processo endogrupal) e negativa diante concepções divergentes de grupos distintos (exogrupo). A exemplo dos discursos dos sujeitos acerca dos sentidos da homofobia, observa-se uma noção de pertença entre os sujeitos que cometem homofobia inseridos em grupos de padrões normativos, e uma coesão ideológica naqueles vistos como dissidentes a partir de suas práticas garantidas por direito e entendida como anti-hegemônicas e combativas pela comunidade LGBT.

De acordo com o conteúdo das falas dos participantes U e K, a homofobia é entendida como uma prática injustificável e sem sentido, uma vez que a essa atitude viola os direitos básicos da vítima, a exemplo da livre expressão e da liberdade de escolha. Estes participantes manifestaram estes sentidos nos discursos:

a homofobia não tem sentido algum, é incompreensível e injustificável que as pessoas possam ser agredidas, humilhadas, violadas de seus direitos, de suas liberdades por expressarem uma sexualidade que é diferente do que a normativa definiu ao longo da história da humanidade e vivenciam uma expressão que é perfeitamente natural e comum durante toda a história da humanidade e em todos os povos que existem sobre a terra $(U)$.

entender a homofobia já é difícil, porque, assim, não tem nenhum sentido para que exista (K). 
Ainda na busca pelos sentidos da homofobia para estudantes universitários, manifesta-se como última categoria a de homofobia como um medo diante uma prática sexual nova. Nesta análise, foi possivel perceber que os elementos atribuídos a esta categoria se assemelham à primeira aqui discutida, emergida de um âmbito sócio-moral. Entretanto, nesta esfera de análise semântica, as manifestações apresentam-se de forma mais denotativas, isto é, mais objetiva e palpável, recheando esta categoria com concepções imbricadas em religiões, historicidade das práticas sexuais e dos modelos de família, além da relação entre os estigmas e as crenças compartilhadas na sociedade. Para elencar este resultado, fez-necessário trazer o discurso do participante $\mathrm{K}$, quando ele diz que

a homofobia é o medo do novo, e tem pessoas, principalmente os mais velhos, os mais conservadores, que tem muito medo do novo por terem sido ensinados lá atrás que isso (a homossexualidade) é errado. Têm muitas pessoas que são ligadas a religião. Eu acho que isso acaba afetando, porque em algum tempo foi dito lá atrás de que isso é errado, de que isso é uma aberração, é pecaminoso, então as pessoas carregam isso e não conseguem se livrar desse estigma, e não conseguem ver duas pessoas do mesmo sexo que se amam e querem estar juntos, e acabam só vendo o lado pecaminoso ou que foi dito errado um tempo atrás (...) são .pessoas que não estão abertas ao novo, não estão abertas a ver que existem mais que uma forma de amor, que existem vários modelos de famílias hoje em dia e que esse modelo de família pai-mãe-filho não é único.

À luz destas categorias de análise e da possível relação com os estudos da psicologia enquanto ciência, um dos pontos importantes a serem discutidos é a questão das relações de poder estabelecidas entre os participantes dos grupos. Para Foucault (1988), o poder e o saber caminham numa mesma direção, mas, a respeito da sexualidade, o poder-saber é concebido como uma prática de controle dos corpos, não apenas da ação ou atitude, mas do pensar e do manifestar-se diante o outro e para o outro, isto é, o poder-saber pode servir como uma ferramenta de controle da afetividade dos sujeitos.

\section{Sentidos do Projeto de Vida}

Dos discursos emitidos pelos sujeitos desta pesquisa, no que diz respeito aos sentidos atribuídos ao fenômeno Projeto de Vida (PV), observou-se a emergência de quatro categorias de análise: 1. PV como conquistas acadêmicas-profissionais, 2. PV relacionado à Qualidade de Vida, 3. PV como realização pessoal e 4. PV como um planejamento afetivo.

Acerca da categoria Projeto de Vida como conquistas acadêmicas-profissionais, foi observada a presença deste conteúdo nos discursos da maioria dos participantes. Como sinalizam os discursos dos participantes Y, T e K, esta categoria tem uma aproximação muito forte com questões econômicas e acadêmicas, além de uma relação direta com os padrões de sucesso concebidos na atualidade social, ancorados na ideia de "mercado de trabalho":

meu projeto de vida se direciona ao termino da graduação e a entrada na pós-graduação (Y).

terminar o curso, arrumar um emprego, me aprimorar nas coisas que eu gosto de fazer, sempre procurando ser uma pessoa melhor, contribuindo para melhoria pessoal e social (T).

meu projeto de vida é fazer o mestrado na área de alemão como língua estrangeiro ou de alemão no geral para seguir como professor da língua alemã. Eu quero fazer mestrado na Alemanha ou então tem outro 
mestrado que me interessa muito em Curitiba, que é um ano em Curitiba e um ano na Alemanha e a princípio eu gostaria muito de ficar por lá (...), o emprego de sonho é trabalhar no DAAD [Deutscher Akademischer Austauschdienst/German Academic Exchance Service] do Goethe Institut (K).

O Projeto de Vida relacionado à Qualidade de Vida traz uma multidimensionalidade de elementos situados num panorama dialogal, dentre eles felicidade, família, corpo saudável, cuidado com a saúde mental e autoestima, demonstrando um desejo de e para o futuro, o qual é socio-historicamente construído desde a infância (Catão, 2007).

a partir do meu projeto de vida desejo proporcionar uma qualidade de vida razoável tanto individualmente quanto para minha família $(Y)$.

e esse é o meu projeto de vida... é ser feliz até onde for possível, tentando manter o corpo saudável e a mente também; 0 amor próprio e a autoestima elevada pra conseguir envelhecer com muita dignidade, felicidade, harmonia e cercado de amigos e boas memórias (U).

Dialogando com Catão (2007), ter acesso ao planejamento individual remonta não somente ao pensamento e à fala, mas à consciência individual ou intersubjetiva do e no vivido. Neste sentido, o acesso à categoria Projeto de Vida como realização pessoal possibilitou o conhecimento acerca dos sentidos atribuídos à felicidade e à realização dos sujeitos aqui em questão:

sei lá, passar cinco anos na china ou no norte da Alemanha, mais dois no Japão, três em um país na América do Sul, mais dois nos Estados Unidos e, assim, nunca ficar fixamente em um canto (K).

meu projeto de vida é realizar meus sonhos, é compreender e ajudar a sociedade a si tornar mais justa, solidaria, participativa, igualitária trabalhar para ser feliz e fazer as coisas que gosto no trabalho na vida, na universidade, na família, e cultivar sempre amigos, famílias, valores como amor, a amizade, a atenção ao outro, a compreensão da diversidade humana, e a harmonia da vida em sociedade (U).

Nesta constelação de desejos, potências e afetividades, manifesta-se como conteúdo da análise dessa classe temática a categoria Projeto de Vida como um planejamento afetivo: "enquanto na relação com uma companheira projeto uma relação estável e forte a fim de enfrentar as possíveis problemáticas, de uma parcela da sociedade, em aceitação de uma relação homossexual" (Y).

Esta categoria vai de encontro aos discursos elaborados por algumas parcelas da sociedade brasileira no período 1980-2000, os quais conceituavam o grupo de homossexuais, neste inseridos homens e mulheres, como promíscuo e incapaz de manter uma relação afetiva e duradoura, influenciando diretamente na concepção de que 0 relacionamento homoafetivo era o mais passível à vulnerabilidade ao vírus do HIV/Aids (Calazans, Pinheiro \& Ayres, 2018). A posição tomada na discussão deste parágrafo é tomada no discurso do participante $K$, quando aborda:

esses dias eu vi um vídeo muito interessante no canal de YouTube que falava de casais homoafetivos que estavam há muito tempo junto (...) porque tem toda essa coisa ninguém quer nada com nada (homossexuais), quer só "ir se pegando" e pronto, e mostram casais que estão há 20 anos juntos.

A discussão trazida por este participante remonta também a um processo de luta contra a hegemonização da identidade dos sujeitos homossexuais, além de uma conjuntura contrária à heteronormatividade como forma de manifestação e expressão da identidade LGBT, tal qual será abordado na categoria 5 do próximo tópico.

No geral, os discursos dos participantes retratam vivências, desejos e afetos sobre si mesmos e sobre 0 mundo, expressando a homofobia como um fenômeno negativo, mas também como algo que incita a resistência e a 
luta por direitos igualitários. Foi perguntado também se eles percebiam a influência da homofobia na construção de seus projetos de vida. Acerca dessa questão, foram encontrados pontos específicos de confluência, como: o projeto de vida diante da homofobia como um processo subjacente às questões de emprego e renda e satisfação pessoal. Para esses sujeitos, o projeto de vida fundamenta-se na luta constante pela visibilidade e direitos igualitários a partir da afirmação da identidade LGBT:

justamente diante da homofobia é que eu projeto a minha trajetória de vida como uma luta constante de afirmação da minha identidade de luta pela visibilidade da minha identidade e da expressão da minha sexualidade e uma luta contra o ódio e as atitudes e os projetos e as políticas que tentem denegrir, humilhar ou retirar direitos da população LGBT (U).

No que tange à Psicologia, é interessante destacar a escassez de discussões sobre esses temas durante a formação profissional dos estudantes, uma vez que os currículos, muitas vezes engessados em uma perspectiva técnica, não favorecem tal debate. Entretanto, salienta-se, de modo louvável, as investidas de alguns professores e instituições que trazem estes assuntos ao contexto da sala de aula de forma transversal, uma vez que mesmo não sendo um assunto próprio da disciplina, é abordado por estar virtualmente conectado a outras questões.

O significado, por sua vez, ora pessoal ora social, atua enquanto um fenômeno intersubjetivo, implicado diretamente nas relações humanas. Neste sentido, buscar os significados é consultar diretamente a consciência dos sujeitos, é permitir que o vivido se expresse numa égide subjetiva, a qual se relaciona politicamente com instâncias universais, mas não finalizados em si mesmos (Vigotsky, 1993).

\section{CONSIDERAÇÕES FINAIS}

Neste estudo percebemos os significados da homofobia e do projeto de vida para um grupo de universitários homossexuais através da análise do conteúdo de seus discursos. Vimos que, para os sujeitos-alvo, este tipo de preconceito pode se apresentar de diferentes formas, desde um pensamento negativo ao ódio dirigido a outra pessoa diante de sua orientação sexual.

Além disso, investigamos se o estigma externo atribuído ao sujeito homossexual, a exemplo da imagem histórica do sujeito gay como vetor do vírus do HIV (Parker \& Aggleton, 2001), apresenta reverberações na construção do planejamento futuro pessoal desse grupo. Um participante reconheceu que a homofobia the faz projetar sua vida como um mote à luta pela igualdade e liberdade sexual. Para os outros três participantes, porém, ficou claro em seus discursos que mesmo que a homofobia seja um problema social a ser combatido, ela não é suficientemente capaz de alterar o projeto de vida individual dessas pessoas.

Pontuamos que este artigo não esgota o debate ou soluciona o problema da homofobia, mas colabora com a literatura científica ao trazer à luz os discursos de lésbicas e gays sobre os sentidos atribuídos ao preconceito considerado como o último tolerável na modernidade (Mott, 2006). Finalmente, dada a pluralidade identitária da comunidade LGBT, sugerimos que as perguntas incitadas nesta pesquisa sejam direcionadas futuramente a pessoas bissexuais e transgêneros, de forma a garantir a representação desses indivíduos nos grupos estudados.

\section{Referências}


Allport, G. (1954). The nature of prejudice. Cambridge: Addison-Wesley.

Borrilo, D. (2015). Homofobia: história e crítica de um preconceito. Belo Horizonte: Autêntica.

Calazans, G. J., Pinheiro, T. F., \& Ayres, J. R. C. M. (2018). Vulnerabilidade programática e cuidado público: panorama das políticas de prevenção do HIV e da Aids voltadas para gays e outros HSH no Brasil. Sexualidad, Salud y Sociedad, 1(29), 263-293. https://dx.doi.org/10.1590/1984-6487.sess.2018.29.13.a

Catão, M. F. (2007). O que pedem as pessoas da vida e o que desejam nela realizar? In E. Kruttzen \& S. Vieira (Orgs.), Psicologia social, clínica e saúde mental (pp. 75-94). João Pessoa: Ed. Universitária.

Foucault, M. (1988). História da Sexualidade: A vontade de saber (Vol. 1). São Paulo: Graal.

GGB - Grupo Gay da Bahia. (2017). Relatório 2016: Assassinatos de LGBT no Brasil. Recuperado em 16 de fevereiro de 2019, de https://homofobiamata.files.wordpress.com/2017/01/relatc3b3rio-2016-ps.pdf

Hammack, P. L., Frost, D. M., Meyer, I. H., \& Pletta, D. R. (2018). Gay Men's Health and Identity: Social Change and the Life Course. Archives of Sexual Behavior, 47(1), 59-74. https://doi.org/10.1007/s10508-017-0990-9

Krueger, R. A., \& Casey, M. A. (2000). Focus groups. A practical guide for applied research. California: Thousand Oaks.

Mott, L. (2006). Homo-Afetividade e Direitos humanos. Revista Estudos Feministas, $\quad$ 14(2), 509-521. https://dx.doi.org/10.1590/S0104-026X2006000200011

Parker, R., Aggleton, P. (2001). Estigma, Discriminação e AIDS. Coleção ABIA, Cidadania e Direitos, v. 1. Rio de Janeiro: Associação Brasileira Interdisciplinar de AIDS.

Sawaia, B. B. (2008). O sofrimento ético-político como categoria de análise da dialética exlucão/inclusão. In B. B. Sawaia (Org.). As artimanhas da exclusão: análise psicossocial e ética da desigualdade social ( $8^{\mathrm{a}}$ ed). Petrópolis: Vozes.

Smith, L. (2017, 15 de abril). Chechnya detains 100 gay men in first concentration camps since the Holocaust. Internacional Business Time. Recuperado http://www.ibtimes.co.uk/chechnya-detains-100-gay-men-first-concentration-camps-since-holocaust-1616363

Sousa, V., \& Arcoverde, L. (2019, 17 de maio). Brasil registra uma morte por homofobia a cada 23 horas, aponta entidade LGBT. G1. https://g1.globo.com/sp/sao-paulo/noticia/2019/05/17/brasil-registra-uma-morte-por-homofobia-a-cada-23-horas-apo nta-entidade-lgbt.ghtml 
Tajfel, H. (1972). La catégorisation sociale. In S. Moscovici (Org.), Introduction à la psychologie sociale (pp. 272-302). Paris: Larousse.

Triviños, A. N. S. (1987). Introdução à pesquisa em ciências sociais: A pesquisa qualitativa em educação. São Paulo, SP: Atlas.

Vala, J. (2003). A Análise de Conteúdo. In A. S. Silva \& J. M. Pinto (Orgs.). Metodologia das Ciências Sociais 101-128). Porto: Edições Afrontamento.

Vigotsky, L. S. (1993). Pensamento e Palavra. São Paulo: Martins Fontes. 


\section{Lista de Tabelas}

Tabela 1 - Características sociodemográficas dos participantes

\begin{tabular}{ccccc}
\hline Participante & Idade & Sexo & Curso & Renda \\
\hline $\mathrm{Y}$ & 21 & Feminino & Ciências & Até 1 salário mínimo \\
$\mathrm{T}$ & 20 & Feminino & Letras Inglês & De 2 a 3 salários \\
& & & & mínimos \\
$\mathrm{U}$ & 48 & Masculino & Psicologia & De 3 a 5 salários \\
$\mathrm{K}$ & 25 & Masculino & Tradução & Até 1 salário mínimo \\
\hline
\end{tabular}

